\title{
MISTURAS ELASTOMÉRICAS DE SBR/BORRACHA NITRÍLICA CARBOXILADA COMPATIBILIZADAS COM POLIACROLEÍNA
}

\section{COMPATIBILIZATION OF SBR/CARBOXYLATED NITRILE RUBBER ELASTOMER BLENDS WITH POLYACROLEIN}

\author{
Z. S. C. NASCIMENTO ${ }^{1, *}$, P. R. PINTO ${ }^{1}$ and A. S. SIRQUEIRA ${ }^{1, *}$
}

${ }^{1}$ Centro Universitário Estadual da Zona Oeste, Escola de Engenharia, Rio de Janeiro, Rio de Janeiro, Brasil

${ }^{*}$ Corresponding author. Centro Universitário Estadual da Zona Oeste, Escola de Engenharia, Rio de Janeiro, Rio de Janeiro, Phone: +552123327530

e-mail addressl: assirqueira@gmail.com (A. S. Sirqueira).

\section{A R T I C L E I N F O}

Article history:

Received 2018-05-08

Accepted 2018-08-27

Available online 2019-03-08

\section{palavras-chave}

Compatibilização

Borracha

Vulcanização

Borracha nitrílica

$\underline{k e y w o r d s}$

Compatibilization

Rubber

Vulcanization

Nitrile rubber
A B S T R A C T

In this work was evaluated the SBR/carboxylated nitrile rubber blends in the proportion of 50:50\%. Due to the differences in polarity between the two elastomers, the blend presents immiscibility and incompatibility, requiring the use of compatibilizing agents. The blends were compatibilized with acrolein oligomer in different proportions (1.5, 2.5 and 5.0). For oligomer synthesis a ratio monomer and initiator of 8 was used. The FTIR results confirmed

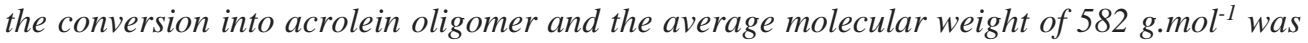
determinate by GPC. The SBR/XNBR blends were processed in a two roll mill and the vulcanization properties were evaluated by oscillatory disk rheometer (ODR). The tensile strength of vulcanized material and degree of swelling in different organic solvents were evaluated, to measure the effect of compatibilizer. The acrolein oligomer acted increasing the crosslinking density of SBR/XNBR blends, observed by the increase in maximum torque value in the ODR. The vulcanization kinetics was catalyzed by the oligomers, increasing in the vulcanization rate by approximately $86 \%$.. The values of tensile strength were higher for compatibilized blends. The oligomer also reduced the degree of swelling in hexane, which corroborates with the rheometry and tensile strength data. The best performance observed was the blend with $2.5 \%$ of acrolein.

R E S U M O

Neste trabalho foi avaliada a mistura elastomérica de SBR/borracha nitrílica carboxilada na proporção de 50:50 \%. Entretanto, devido às diferenças de polaridade entre os dois elastômeros a mistura apresenta imiscibilidade e incompatibilidade, sendo necessária a utilização de agentes compatibilizantes. As misturas foram compatibilizadas com o oligômero de acroleína em diferentes proporções (1,5; 2,5 e 5,0). Na síntese do oligômero, utilizou-se a razão de monômero/iniciador de 8. Os resultados de FTIR confirmaram a conversão no oligômero e, através de GPC, determinou-se a massa molecular ponderal média de 582 g.mol ${ }^{-1}$. As misturas elastoméricas de SBR/XNBR foram processadas em misturador aberto de rolos, em seguida foram avaliadas as propriedades de vulcanização em reômetro de disco oscilatório (RDO), a resistência à tração e o grau de inchamento em diferentes solventes orgânicos. O oligômero de acroleína atuou aumentando a densidade de ligações cruzadas da mistura SBR/XNBR, confirmado pelo aumento no valor de torque máximo no RDO. A cinética de vulcanização também foi catalisada pela presença dos oligômeros, observado pelo aumento de, aproximadamente, $86 \%$ na taxa de vulcanização em relação à mistura não compatibilizada. Os resultados de resistência à tração foram superiores para as misturas compatibilizadas. A presença do oligômero também reduziu o grau de inchamento em hexano, o que corrobora com os dados de reometria e resistência à tração. O teor de acroleína que apresentou o melhor desempenho foi de 2,5\%. 


\section{INTRODUÇÃO}

A técnica de misturas poliméricas é muito empregada na indústria, a fim de melhorar as propriedades finais dos artefatos produzidos, visto que os polímeros isolados não conseguem atingir múltiplos desempenhos mecânico sem o desenvolvimento de novas rotas sintéticas. Porém, o sinergismo de propriedades raramente é alcançado com a simples mistura física entre dois polímeros, isto acontece devido às diferenças estruturais, de polaridade e de viscosidade dos pares poliméricos envolvidos na mistura, resultando na incompatibilidade. Para solucionar o problema, utilizam-se os agentes interfaciais que são capazes de promover, a ligação covalente entre os dois polímeros (Carvalho and Sirqueira, 2016; Moreira and Soares, 2002; Sirqueira et al., 2009).

Misturas elastoméricas requerem maior atenção e cuidado especial, pois, além dos problemas apontados, existe a incompatibilidade de taxa de vulcanização. Esta incompatibilidade é gerada pelas diferenças de velocidades de vulcanização entre os pares elastoméricos (Souto et al., 2017). A densidade de ligações químicas produzidas ao final da vulcanização apresentará distribuição heterogênea (Carvalho and Sirqueira, 2016; Sirqueira et al., 2009; Soares et al., 2002). Devido ao grande interesse industrial vários autores têm estudado soluções para obter um material vulcanizado com a mesma densidade de ligações cruzadas entre as fases, a este estado dá-se o nome de co-vulcanização (Sirqueira and Soares, 2003).

O copolímero de estireno-butadieno (SBR) é um dos elastômeros sintético mais utilizado pela indústria de pneumáticos e também pela indústria de maneira geral. O interesse é em função da facilidade de processamento do SBR e ao seu baixo custo de produção. A mistura do SBR com outros elastômeros é frequentemente utilizada e busca-se com isto o sinergismo de propriedades. Alguns exemplos são a mistura com a borracha natural (BN) (Mansila et al., 2016; Shen et al., 2013), com o polibutadieno (BR) (Malas at al., 2014; Mokhtari and Schipper, 2016), com o terpolímero de etileno-propileno-dieno (EPDM) (Betron et al., 2016) e a com borracha nitrílica (NBR) (Choi and Kim, 2012; Khalf et al., 2010; Mostafa and Abouel-Kasem, 2009).

Porém, o par SBR/NBR requer atenção, em virtude da grande diferença de polaridade entre os elastômeros e a afinidade dos aceleradores pela fase NBR, resultando em uma mistura com incompatibilidades de polaridade e de taxa de vulcanização. Alguns autores utilizam a técnica da compatibilização reativa para ancorar quimicamente as duas fases elastoméricas. Para utilizar esta técnica, é necessária a presença de grupos reativos em uma das fases. Um exemplo da modificação química na borracha nitrílica é a inserção de ácido carboxílico na cadeia principal da borracha, XNBR (borracha nitrílica carboxilada). A XNBR apresenta em sua cadeia a inserção de grupos de ácido carboxílico, aproximadamente 7\%, é comercializada com diferentes viscosidades Mooney e teores de acrilonitrila (Oliveira et al., 2009).
Misturas envolvendo o par elastomérico SBR/XNBR, teoricamente, produziria um material com alto módulo elástico, alta resistência ao desgaste e de baixo custo, o que tornaria o material competitivo industrialmente, caso ocorresse $o$ sinergismo de propriedades. Entretanto, a simples mistura física de SBR com XNBR produz um material elastomérico imiscível e incompatível, devido principalmente à grande diferença de polaridade, resultando em uma mistura final com propriedades mecânicas inferiores a dos elastômeros iniciais. Assim, é necessário o uso de compatibilizante anfifílico, capaz de reagir com os elastômeros (Celestino and Soares, 2013).

O agente compatibilizante escolhido para o estudo deste trabalho foi o oligômero de acroleína, devido à sua baixa viscosidade e à presença de grupos polares na cadeia principal. A baixa viscosidade do oligômero aproximar-se-á da fase de menor viscosidade e os grupos polares presentes na cadeia polimérica da fase XNBR. Desta maneira, poderá ocorrer a reação de vulcanização na fase insaturada da borracha SBR e a ligação iônica do aldeído/ácido carboxílico com o óxido de zinco utilizado na vulcanização (Cossa et al., 2014).

A acroleína é um monômero muito reativo que possui um sistema de duplas ligações conjugadas e pode ser polimerizado por: via radical livre, catiônica e aniônica. A Figura 1 apresenta a rota sintética do oligômero de poliacroleína.

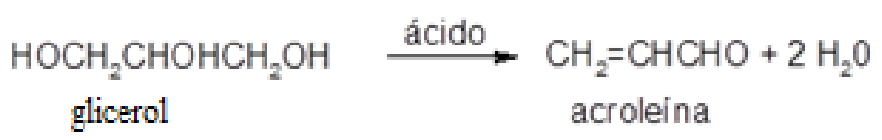

Figura 1. Rota sintética da acroleína.

As sínteses da acroleína por via radical livre e catiônica levam a polímeros insolúveis, mesmo a baixas taxas as de conversão (Guilino et al., 1981). Em contrapartida, a polimerização aniônica pode conduzir a polímeros lineares solúveis. A acroleína pode polimerizar pela abertura de três ligações diferentes: $(1,2)$; $(1,4)$; e $(3,4)$. Desta maneira, pode-se encontrar na microestrutura dos oligômeros de acroleína grupamentos aldeído, ligações duplas, grupos éter vinílico e éter alifático.

Devido às várias possibilidades de ligações, optou-se por estudar este oligômero como potencial agente compatibilizante para reduz a tensão interfacial entre o par SBR/XNBR. A Figura 2 apresenta o sistema sem compatibilizante (com alta tensão interfacial) e com o compatibilizante da poliacroleína (as duas fases estão ligadas quimicamente com a poliacroleína). 


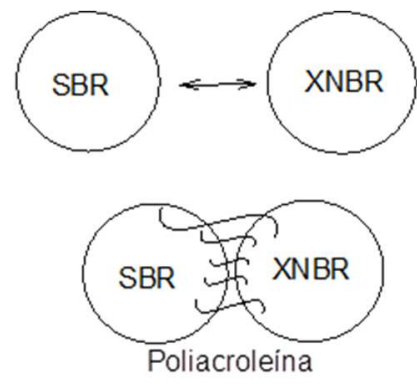

Figura 2. Esquema representativo da mistura SBR/XNBR, (a) sem o agente compatibilizante $\mathrm{e}$ (b) com o agente compatibilizante.

\section{MATERIAIS E MÉTODOS}

Os elastômeros utilizados foram: borracha do copolímero estireno-butadieno, SBR N-1502 (viscosidade Mooney $=60 \mathrm{e}$ polimerização a frio) e a borracha nitrílica carboxilada, XNBR $3350 X$ (teor de acrilonitrila $=26-28 \%$, viscosidade Mooney $=48$, teor de carboxila $=7 \%$ e processo de polimerização a frio), ambas doadas gentilmente pela empresa Nitriflex Indústria e Comércio, Rio de Janeiro, Brasil. Terc-butil lítio utilizado na síntese da acroleína foi produzido pela empresa Sigma Aldrich, São Paulo, Brasil. O sistema de vulcanização utilizado foi composto por Óxido de Zinco, Ácido Esteárico, CBS e Enxofre, todos adquiridos da empresa Parabor, São Paulo, Brasil. O tetrahidrofurano, clorofórmio e hexano foram fornecidos pela Vetec, Rio de Janeiro, Brasil.

\subsection{Síntese do oligômero de acroleína}

Os oligômeros de acroleína foram sintetizados via aniônica, usando como iniciador o terc-Butil lítio em tetrahidrofurano seco, em atmosfera de gás nitrogênio, numa temperatura de $-90^{\circ} \mathrm{C}$. As massas molares médias (Mn e Mw) do oligômero de acroleína foram determinadas por cromatografia de permeação (GPC). O Sistema de GPC foi equipado com uma bomba da Waters 600E (Milford, MA, USA), e uma válvula de injeção Rheodyne 7125 (Cotati, USA), e detector Waters 2996 photodiode (Milford, MA, USA). A utilizada foi a coluna SB804 (adquirida da empresa SHODEK, Yokohama, Japão), utilizando como solvente uma solução contendo $\mathrm{LiCl}$ 0,05 M em DMF:H2O (1:1) (Guilino et al., 1981).

\subsection{Mistura elastomérica}

A formulação utilizada para avaliar o efeito do oligômero de acroleína como agente compatibilizante, da mistura SBR/XNBR, é apresentada na Tabela 1. As misturas de SBR e XNBR foram processadas durante 5 minutos em misturador interno com capacidade de mistura de $120 \mathrm{~cm}^{3}$, velocidade de 60 RPM e temperatura controlada de $50^{\circ} \mathrm{C}$. Inicialmente foi processada a borracha de SBR por 1 minuto, após este intervalo de tempo a borracha de XNBR foi adicionada por 2 minutos, em seguida o óxido de zinco, e manteve-se o processamento por mais 2 minutos. As misturas foram resfriadas, e armazenadas por 24 horas. O reprocessamento foi realizado em um misturador de cilindros, para incorporação dos agentes de vulcanização, nas seguintes condições: temperatura de $50^{\circ} \mathrm{C}$, velocidade os cilindros de 20 e 24 RPM, tempo total de mistura de 10 minutos. Adição do sistema de vulcanização foi na seguinte ordem: ácido esteárico, enxofre, CBS, com intervalo de tempo entre cada adição de dois minutos. O óxido de zinco foi adicionado na primeira etapa de mistura para facilitar a sua dispersão na fase XNBR e também, para formação de ligações iônicas.

Tabela 1 - Formulação das misturas SBR/XNBR em percentagem.

\begin{tabular}{lllll} 
SBR & $\mathbf{1}$ & $\mathbf{2}$ & $\mathbf{3}$ & $\mathbf{4}$ \\
XNBR & 50 & 50 & 50 & 50 \\
Acroleina & 50 & 50 & 50 & 50 \\
ZnO & 0 & 1 & 2,5 & 5 \\
Ácido & 5 & 5 & 5 & 5 \\
Esteárico & 2 & 2 & 2 & 2 \\
Enxofre & 2 & 2 & 2 & 2 \\
CBS & 1 & 1 & 1 & 1 \\
\hline
\end{tabular}

Os parâmetros de vulcanização das misturas foram determinados a partir dos dados fornecidos pelo reômetro de disco oscilatório, RDO, norma ASTM D-2084-11. As condições de análise foram: arco de oscilação de $1^{\circ}$, tempo de vulcanização de 24 minutos e temperatura de $170^{\circ} \mathrm{C}$. A taxa de vulcanização (CRI) foi calculada utilizando a Equação 1.

$C R I=100 /\left(t_{90}-t_{s 1}\right)$

Em que: $t_{90}$ é o tempo ótimo de cura e $t_{s 1}$ é o tempo de segurança.

\subsection{Ensaios mecânicos e de inchamento}

A moldagem dos corpos de prova foi realizada em prensa hidráulica a $170^{\circ} \mathrm{C}$, utilizando os parâmetros de vulcanização obtidos através do RDO.

Os corpos de prova para o ensaio de resistência à tração foram obtidos de acordo com a norma DIN 53504-10. O ensaio foi realizado em máquina universal de ensaios, com velocidade de separação entre as garras de $200 \mathrm{~mm} \cdot \mathrm{min}^{-1}$.

A resistência ao inchamento em solvente orgânico foi realizada para determinar a densidade de ligações cruzadas nas misturas. A metodologia consistiu em vulcanizar as amostras no tempo ótimo de cura, fornecido pelo RDO, preparar corpos de prova, pesar e imergi-los em diferentes solventes (clorofórmio e hexano). O ensaio foi conduzido até atingir peso constante (equilíbrio), obtido após 48 horas de imersão. O grau de inchamento (G.I.) foi calculado utilizando a Equação 2.

G.I. $=\left[M_{\text {inchada }}-M_{\text {seca }} / M_{\text {seca }}\right] * 100$

Em que: $\mathbf{M}_{\text {inchada }}=$ Massa Inchada $; \mathbf{M}_{\text {seca }}=$ Massa antes da imersão em solvente. 


\section{RESULTADOS E DISCUSSÃO}

Os valores obtidos por cromatografia de permeação em gel para as massas molares dos oligômeros de acroleína foram: Massa molecular ponderal média $(\mathrm{Mw})=582 \mathrm{~g} \cdot \mathrm{mol}^{-1}$, massa molecular numérica média $(\mathrm{Mn})=314 \mathrm{~g} \cdot \mathrm{mol}^{-1} \mathrm{e}$ polidispersão $(\mathrm{Mw} / \mathrm{Mn})=1,8$.

Na Figura 3 é mostrado o resultado das análises de FTIR dos oligômeros de acroleína, e revelam a presença das microestruturas correspondentes às três inserções monoméricas possíveis na cadeia. As inserções monoméricas $(1,2)$ foram confirmadas pela presença de absorções referente à carbonila de aldeído; as inserções $(3,4)$ correspondem à presença do grupo vinílico monossubstituído e as inserções $(1,4)$ são referentes ao éter vinílico. A presença de grupamentos aldeído nos oligômeros foi confirmada por meio do aparecimento de absorções referentes ao estiramento da carbonila na faixa de $1740-1720 \mathrm{~cm}^{-1}$, absorções referentes à deformação assimétrica de $\mathrm{CH}$ na faixa de $1410-1380 \mathrm{~cm}^{-1}$ e pela presença de um doublet característico na faixa de $2830-2810 \mathrm{~cm}^{-1}$ e $2720-2695$ $\mathrm{cm}^{-1}$. Em todas as amostras, foi verificada a presença do grupo aldeído e, consequentemente, a inserção monomérica $(1,2)$ na microestrutura dos oligômeros, conforme pode ser observado no espectro vibracional. Os grupamentos vinílicos monossubstituídos foram confirmados pelo aparecimento da absorção em torno de $3080 \mathrm{~cm}^{-1}$ que pode ser atribuída ao estiramento de $=\mathrm{CH}_{2}$ de grupos vinílicos terminais.

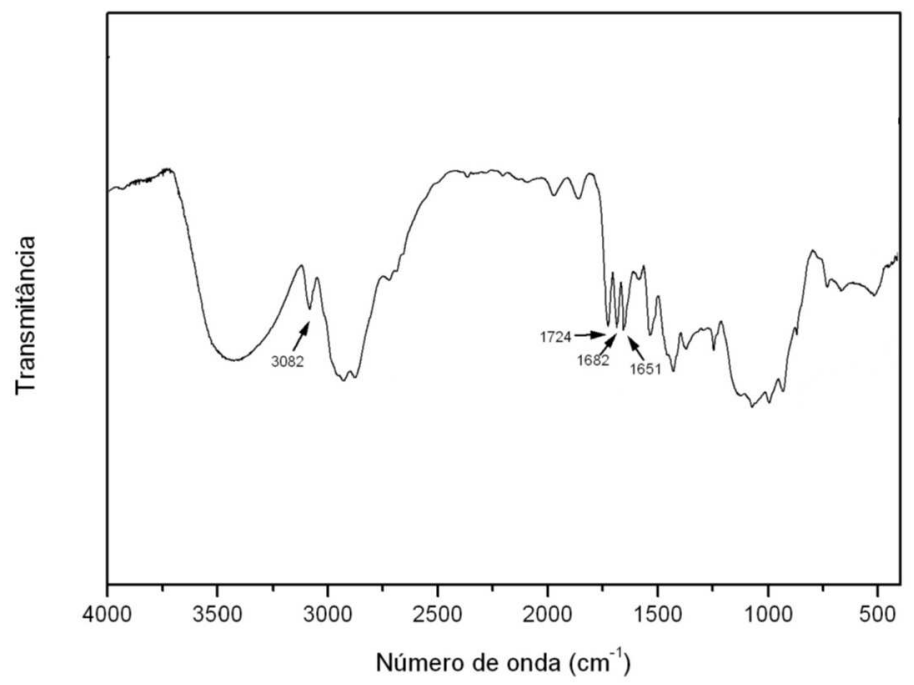

Figura 3. FTIR para o oligômero de acroleína.

Uma das principais caracterizações empregadas na tecnologia de elastômeros é a caracterização reométrica. Com o uso do reômetro de disco oscilatório, estuda-se todo o processo de vulcanização. Através dos dados obtidos pelo reômetro, pode-se avaliar a eficiência do sistema de vulcanização utilizado nas formulações, a influência na cinética de vulcanização, o efeito da temperatura na vulcanização, o início do processo de degradação e outras. Os principais parâmetros obtidos são: torque máximo, torque mínimo, tempo ótimo de cura e taxa de vulcanização (Cossa et al., 2014; Mokhtari and Schipper, 2016).
A Tabela 2 apresenta os parâmetros de vulcanização obtidos das misturas de SBR/XNBR, na temperatura de $170^{\circ} \mathrm{C}$. Nota-se que a adição do oligômero de acroleína aumenta o valor do torque mínimo, o que indica aumento na viscosidade da final mistura, pois o torque mínimo, $\mathrm{M}_{\mathrm{L}}$, está relacionado com a viscosidade do material não vulcanizado. Pode-se atribuir esse comportamento as possíveis interações entre os grupos aldeído da acroleína e ácido carboxílico da borracha nitrílica carboxilada com o óxido de zinco da formulação (Cossa et al., 2014; Mokhtari and Schipper, 2016).

O aumento no valor de torque máximo em composições elastoméricas indica aumento na quantidade de ligações cruzadas dos compósitos. Nota-se que a adição do oligômero de acroleína produz aumento na quantidade de ligações cruzadas. Cossa et al. (2014) ao estudar diferentes sistemas de vulcanização para a borracha nitrílica carboxilada notou a competição em sistemas polares pelo óxido de zinco. No estudo observou-se a formação do ionômero entre o óxido de zinco e o grupo carboxílico da borracha XNBR, o que aumentou a resistência mecânica do material. Nas misturas compatibilizadas com o oligômero de acroleína provavelmente ocorre esta interação e sugere-se a formação do ionômero também com o aldeído.

Nota-se que as misturas compatibilizadas com o oligômero de acroleína apresentaram tempo ótimo de cura inferior ao da mistura não compatibilizada, cerca de 40\%. Este comportamento sugere que o oligômero de acroleína atua no sistema de vulcanização das misturas, favorecendo a formação das reticulações sulfídicas. Outro resultado que corrobora esta hipótese é o aumento na taxa de vulcanização (CRI). Pode-se atribuir a presença dos grupos polares da acroleína como responsáveis pelo aumento na velocidade de reticulação das amostras compatibilizadas.

\section{Tabela 2. Parâmetros de vulcanização das amostras} SBR/XNBR a $170{ }^{\circ} \mathrm{C}$.

\begin{tabular}{cccccc}
\hline Amostras & $\begin{array}{c}\mathrm{M}_{\mathrm{L}} / \\
\mathrm{lb} . \mathrm{in}\end{array}$ & $\begin{array}{c}\mathrm{M}_{\mathrm{H}} / \\
\mathrm{lb} . \mathrm{in}\end{array}$ & $\begin{array}{c}\mathrm{t}_{\mathrm{s} 1} / \\
\mathrm{min} .\end{array}$ & $\begin{array}{c}\mathrm{t}_{90} / \\
\mathrm{min} .\end{array}$ & $\begin{array}{c}\mathrm{CRI} / \\
\text { min. }^{-1}\end{array}$ \\
\hline 01 & 2,1 & 22,4 & 2,40 & 9,12 & 14,88 \\
03 & 3,8 & 24,9 & 1,82 & 5,75 & 25,44 \\
04 & 3,9 & 23,3 & 1,89 & 5,57 & 27,00 \\
05 & 3,8 & 23,0 & 1,70 & 5,75 & 24,69 \\
\hline
\end{tabular}

$\mathrm{M}_{\mathrm{L}}=$ torque mínimo; $\mathrm{M}_{\mathrm{H}}=$ torque máximo; $\mathrm{t}_{\mathrm{s} 1}=$ tempo de précura; $t_{90}=$ tempo ótimo de cura.

Os resultados obtidos para as propriedades mecânicas, de resistência à tração e alongamento na ruptura, são apresentados na Figura 4. Observa-se o aumento no teor de acroleína, afeta diretamente o valor da resistência à tração na ruptura e o alongamento das amostras vulcanizadas. Este resultado corrobora o comportamento observado para o torque máximo no reômetro de disco oscilatório. O aumento foi de, aproximadamente, $260 \%$ no valor de resistência à tração, confirmando o aumento na densidade de ligações cruzadas da amostra com 5 pcr de acroleína. O oligômero de acroleína além de aumentar a densidade de ligações cruzadas provocou aumento na taxa de formação de ligações cruzadas (CRI). 
Assim, este compatibilizante atua aumentando e acelerando a formação de uma rede tridimensional de ligações cruzadas.

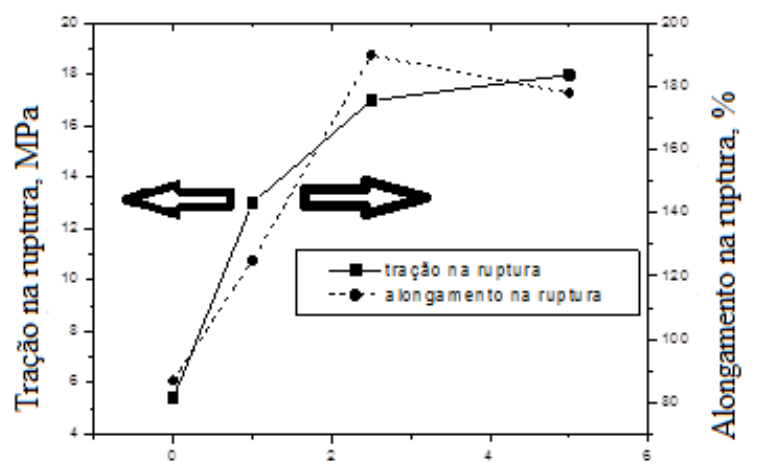

Teor de compatibilizante, pcr

Figura 4. Ensaio de tração-deformação.

O ensaio de inchamento em solvente orgânico foi utilizado com o intuito de determinar qualitativamente a densidade de ligações cruzadas na mistura. Quanto maior a quantidade de ligações cruzadas, menor será o percentual de borracha inchada. Desta maneira, avalia-se indiretamente a eficiência do sistema de vulcanização, na formação de ligações covalentes (Mokhtari and Schipper, 2016; Sirqueira et al., 2009).

O grau de inchamento em hexano é apresentado na Figura 4. Nota-se que as misturas compatibilizadas apresentam menores valores de inchamento, este comportamento sugere que as misturas compatibilizadas têm número de ligações cruzadas maior. O que confirma o efeito da Poliacroleína como agente compatibilizante da mistura, entretanto, não foi observado redução no grau de inchamento com aumento do teor de Poliacroleína. O solvente orgânico hexano apresenta parâmetro de solubilidade próximo ao parâmetro de solubilidade da SBR. Assim a fase SBR terá maior afinidade com o solvente e o aumento pode estar relacionamento a esta fase. As misturas estudadas neste trabalho estavam na razão 50:50, desta forma a redução no valor pode estar relacionado ao aumento na densidade de ligações cruzadas da fase SBR. Pode-se especular que ocorreu compatibilização com a fase SBR. Para verificar se ocorreu aumento na densidade de ligações cruzadas da fase XNBR, o solvente polar clorofórmio foi utilizado. O parâmetro de solubilidade do clorofórmio é próximo ao da XNBR.

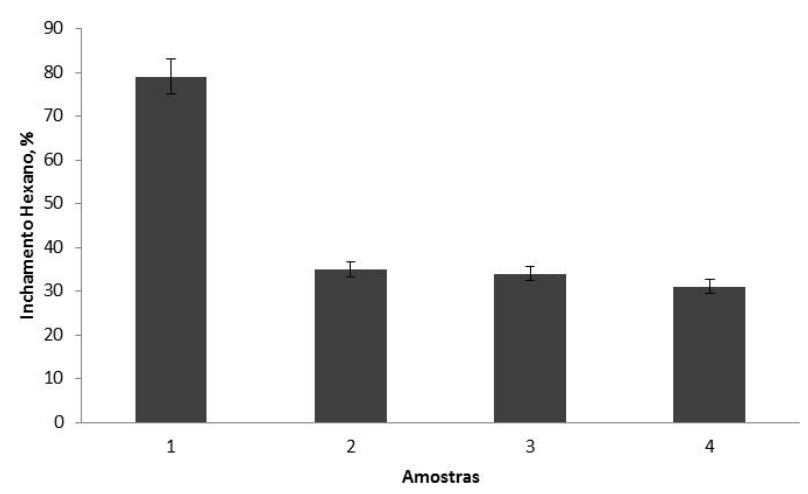

Figura 5. Inchamento em hexano das misturas SBR/XNBR.
A Figura 6 apresenta o grau de inchamento das misturas SBR/XNBR em clorofórmio. Os valores do inchamento das misturas compatibilizadas são superiores ao da mistura não compatibilizada, o que sugere que a fase XNBR não foi curada totalmente. Pode-se atribuir este comportamento a destruição pelo solvente das interações iônicas entre o óxido de zinco e os grupos carboxílicos e aldeído presente nas misturas compatibilizadas (Cossa et al., 2014; Sirqueira and Soares, 2002).

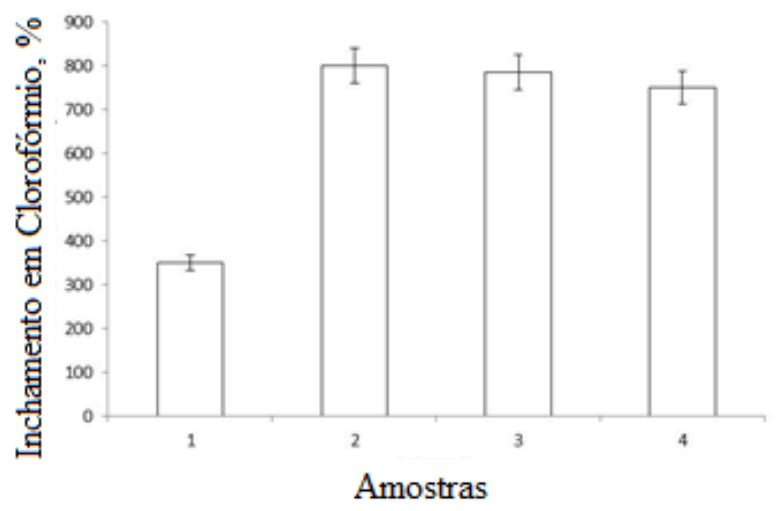

Figura 6. Inchamento em clorofórmio das misturas SBR/XNBR.

\section{CONCLUSÕES}

Pode-se concluir com os resultados apresentados neste trabalho que ocorreu a compatibilização reativa entre as fases elastoméricas do par incompatível SBR/XNBR. Esta compatibilização foi provocada pela adição do oligômero de acroleína com polidispersão de 1,8 e massa molécula numérica média de 314 g.mol ${ }^{-1}$.

Dentre os teores de acroleína estudados o que apresentou maior resistência à tração foi com 2,5 pcr de compatibilizante. $\mathrm{O}$ incremento de acroleína na mistura não produziu aumento na resistência à tração e no inchamento para os solventes analisados.

A presença do oligômero de acroleína influenciou na cinética de vulcanização das misturas SBR/XNBR. O índice de cura teve aumento de $100 \%$ para o teor e 2,5 pcr.

O inchamento da mistura SBR/XNBR em solventes comprovou a forma de atuação do oligômero nas diferentes fases da mistura elastomérica. $\mathrm{O}$ oligômero interagiu durante a vulcanização com a fase SBR, aumentando a densidade de ligações cruzadas. Na fase XNBR o oligômero atuou aumentando a formação do ionômero entre os grupos carboxílicos e óxido de zinco.

\section{AGRADECIMENTOS}

Os autores agradecem o suporte financeiro da FAPERJ e CNPq. 


\section{R E F E R E N C E S}

BÉTRON, C., CASSAGNAU, C., LEGARÉ, V. . Control of diffusion and exudation of vegetable oils EPDM copolymers. European Polymer Journal, v. 82, p. 102-113, 2016

CARVALHO, A. P. A. DE; SIRQUEIRA, A. DA S. Effect of compatibilization in situ on PA/SEBS blends. Polímeros, 2016.

CELESTINO, M. L., SOARES, B. G. Compatibilization efficiency of carboxylated nitrile rubber and eopxy prepolymer in nitrile/acrylic rubber blends. Polimeros, v. 23, p. 139-143, 2013.

CHOI, S. S., KIM, J. C. "Lifetime predicition and thermal aging behaiors of SBR and NBR composites using crosslink density changes. Industrial and Engineering Chemistry, v. 18, p. 1166-1170, 2012.

COSSA, M. M., CARVALHO, A.P.A., SIRQUEIRA, A. S. Cinética de reticulação de borracha nitrílica carboxilada. ActaScientiae et Technicae, v. 2, p. 1317,2014

GUlinO, D., GOLÉ, J., PASCAULT, J. Polymerisation anionique de lácroléine 2: Influence de la nature du contre-ion et de la température sur la cinétique de la réaction. Makromolecule Chemie, p. 1215-1227, 1981.

KHALF, A. F., NASHAR, D., MAZIAD, M. A. Effect of grafting cellulose acetate and methylmethacrylate as compatibilizer onto NBR/SBR blends. Materials \& Design, v. 31, p. 2592-2598, 2010.

MALAS, A., PAL, P., DAS, D. K. Effect of expanded graphite and modified graphite flakex on the physical and thermo-mechanical properties of styrene butadiene rubber/polybutadiene rubber (SBR/BR) blends. Materials \& Design, v. 55, p. 664-673, 2014.

MANSILLA, M.A., VALENTÍN,J.L., ET. AL. "Effect of entanglements in the microstructure of cured NR/SBR blends prepared by solution and mixing in a two roll mill. European Polymer Journal, v. 81, p. 365-375,
2016.

MOKHTARI, M., SCHIPPER, D. . Existence of a tribomodified surface layer of BR/SBR elastomers reinforced with silica or carbon black. Tribology International, v. 96, p. 382-388, 2016.

MOREIRA, V. X.; SOARES, B. G. Study of utilization of ground EVA waste as filler in NBR vulcanizates. Polymers and Polymer Composites, 2002.

MOSTAFA, A., ABOUEL-KASEM, A. Effect of carbon black loading on the swelling and compression set behavior of SBR and NBR rubber compounds. Materials \& Design, v. 30, p. 1561-1568, 2009.

OLIVEIRA, M.G., SILVA, M.O., E. AL. Cinética de vulcanização de borracha nitrílica carboxilada. gresso Brasileiro de Polímeros. Anais...2009.

SHEN, J., WEN, S., E. AL. The network and properties of the NR/SBR vulcanizate modified by electron beam irradiaton. Radiation physics and chemistry, v. 92, p. 99-104, 2013.

SIRQUEIRA, A. S. et al. Nitrigreen a Borracha Ecológica. Revista polímeros, v. 19, p. 10-13, 2009.

SIRQUEIRA, A. S.; SOARES, B. G. Mercapto-modified copolymers in elastomer blends. IV. The compatibilization of natural rubber/EPDM blends. Journal of Applied Polymer Science, 2002.

SIRQUEIRA, A. S.; SOARES, B. G. The effect of mercaptoand thioacetate-modified EPDM on the curing parameters and mechanical properties of natural rubber/EPDM blends. European Polymer Journal, 2003.

SOARES, B. G. et al. The reactive compatibilization of EPDM-based elastomer blends. KGK-Kautschuk und Gummi Kunststoffe, 2002.

SOUTO, L. F. et al. Estudo das propriedades reológicas , mecânicas e de blindagem eletromagnética de misturas elastoméricas envolvendo borracha nitrílica ( NBR ) e borracha nitrílica carboxilada ( XNBR ) Study of rheological, mechanical and electromagnetic shielding propert. v. 27, p. 14-19, 2017. 